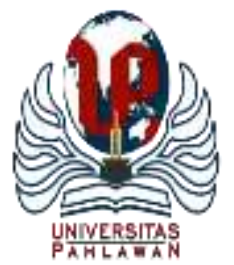

Edukatif : Jurnal Ilmu Pendidikan Volume 3 Nomor 6 Tahun 2021 Halm 4700 - 4707

EDUKATIF: JURNAL ILMU PENDIDIKAN

Research \& Learning in Education

https://edukatif.org/index.php/edukatif/index

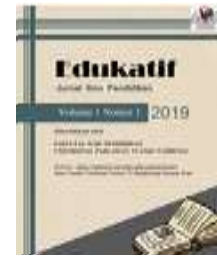

\title{
Pengaruh Media Audio Visual Terhadap Keterampilan Gerak Tari Siswa Sekolah Dasar
}

\author{
Ritu Suwitri $^{1 凶}$, Ana Novitasari ${ }^{2}$, Raimon Effendi ${ }^{3}$
}

Universitas Dharmas Indonesia, Indonesia ${ }^{1,2,3}$

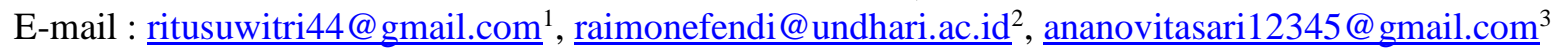

\begin{abstract}
Abstrak
Penelitian ini di latarbelakangi oleh rendahnya minat belajar seni tari, kurangnya keseriusan siswa dalam pembelajaran seni tari, kurang antusias dalam mengikuti gerakan tari, dan kemampuan gerak tari siswa yang masih kaku. Adapun rumusan masalah sebagai berikut, Adakah Pengaruh Terhadap Penggunaan Media Audio Visual Pada Keterampilan Gerak Tari Siswa Kelas IV.1 SD Negeri 08 Sungai Rumbai. Tujuan dari penelitian ini adalah untuk mengetahui apakah ada pengaruh media Audio Visual dalam bentuk video pada keterampilan gerak tari siswa dalam pelajaran seni budaya dan prakarya (SBdP) kelas IV SD Negeri 08 Sungai Rumbai. Jenis penelitian yang digunakan adalah Pre Experimental Design dengan desain penelitian One Group Pretest-Posttest Design. Penelitian ini dilakukan di SDN 08 Sungai Rumbai. Sampel pada penelitian ini berjumlah 32 siswa. Waktu dilaksanakannya penelitian ini pada semester II Tahun Ajaran 2021, disesuaikan pada jadwal pelajaran SBdP kelas IV SDN 08 Sungai Rumbai. Hasil posttest menunjukkan tingkat ketuntasan sebesar 75,97\%. Dari hasil Uji Paired Samples T Test diperoleh signifikansi $0,000<0,05$. Maka dapat disimpulkan bahwa Media Audio Visual dalam bentuk Video dapat berpengaruh terhadap keterampilan gerak tari siswa kelas IV.1 SD Negeri 08 Sungai Rumbai.
\end{abstract}

Kata Kunci: Media, Audio Visual, Gerak Tari.

\begin{abstract}
This research is motivated by the low interest in learning dance, the lack of seriousness of students in learning dance, less enthusiasm in following dance movements, and the ability of students to dance movements that are still stiff. The formulation of the problem is as follows, is there an influence on the use of audiovisual media on the dance skills of students in class IV.1 SD Negeri 08 Sungai Rumbai. The purpose of this study was to determine whether there was an effect of Audio Visual media in the form of videos of students' dance movement skills in class IV arts and crafts lessons (SBdP) SD Negeri 08 Sungai Rumbai. The type of research used is Pre Experimental Design with a research design of One Group Pretest-Posttest Design. This research was conducted at SDN 08 Sungai Rumbai. The sample in this study found 32 students. The implementation time of this research is in the second semester of the 2021 Academic Year, adjusted to the class IV SBdP lesson schedule at SDN 08 Sungai Rumbai. The posttest results showed a completeness level of 75.97\%. From the results of the Paired Samples T-Test, a significance of $0.000<0.05$ was obtained. So it can be said that Audio-Visual Media in the form of Video can affect the dance skills of fourth-grade students of SD Negeri 08 Sungai Rumbai.
\end{abstract}

Keywords: Media, audio visual, dance moves

Copyright (c) 2021 Ritu Suwitri, Ana Novitasari, Raimon Effendi

$\triangle$ Corresponding author:

Email : ritusuwitri44@gmail.com

DOI : https://doi.org/10.31004/edukatif.v3i6.1539

ISSN 2656-8063 (Media Cetak)

ISSN 2656-8071 (Media Online)

Edukatif : Jurnal Ilmu Pendidikan Vol 3 No 6 Tahun 2021 p-ISSN 2656-8063 e-ISSN 2656-8071 
4701 Pengaruh Media Audio Visual Terhadap Keterampilan Gerak Tari Siswa Sekolah Dasar - Ritu Suwitri, Ana Novitasari, Raimon Effendi

DOI: https://doi.org/10.31004/edukatif.v3i6.1539

\section{PENDAHULUAN}

Berdasarkan Undang-Undang Republik Indonesia Nomor 20 Tahun 2003 tentang Sistem Pendidikan Nasional Pasal 1 menyatakan bahwa pendidikan adalah usaha sadar dan terencana untuk mewujudkan suasana belajar dan proses pembelajaran agar peserta didik terlibat secara aktif mengembangkan potensi dirinya untuk memiliki kekuatan spiritual keagamaan, pengendalian diri, kepribadian, kecerdasan, akhlak mulia, serta keterampilan yang diperlukan dirinya, masyarakat, bangsa dan negara. Rosala (2016) mengatakan bahwa pendidikan adalah upaya sadar guru untuk mengirim informasi dan kualitas yang berlaku di arena publik untuk siswa. Adapun menurut (Sujana, 2019) Pendidikan adalah upaya untuk membantu jiwa anak didik baik lahir maupun batin, dari sifat kodratinya menuju kearah peradaban manusiawi yang lebih baik. Maka sekolah dijadikan tempat pelaksanaan pendidikan formal sejak dini yang memberikan kesempatan siswa untuk meningkatkan potensi, bakat serta minat melalui proses belajar (Hanny Pramitha Putri, 2021). Dengan bersekolah dipercaya setiap individu dapat menumbuhkan kemungkinan yang ada dalam dirinya sehingga menjadi pribadi yang memiliki pengetahuan nalar, kemampuan, dan akhlak yang baik. Sesuai dengan fungsi Pendidikan Nasional menurut UU Sisdiknas pasal 3 menyatakan bahwa: "Membina kemampuan dan membentuk pribadi dan kemajuan negara yang terhormat untuk mencerdaskan kehidupan negara, dan berharap dapat menumbuhkan kemampuan siswa menjadi pribadi yang bertakwa, bertakwa kepada Tuhan Yang Maha Kuasa, berbudi pekerti luhur, berakhlak mulia, berilmu, cakap, berimajinasi , mandiri, dan menjadi penduduk. berdasarkan popularitas dan dapat diandalkan. Sehingga cenderung dianggap bahwa pelatihan adalah pendidikan tentang ilmu pengetahuan dan kualitas yang berlaku di arena publik untuk siswa yang berharga untuk bekerja pada kepuasan pribadi.

Kurikulum 2013 (K-13) adalah kurikulum yang berlaku dalam sistem pendidikan di Indonesia. Dalam Kurikulum 2013 (K-13), terdapat sejumlah mata pelajaran yang salah satunya adalah Seni Budaya dan Prakarya (SBdP). Mata pelajaran Seni Budaya dan Prakarya (SBdP) mengajarkan tentang berbagai macam seni budaya Indonesia, salah satunya adalah seni tari. Menurut Setiawan, (2019) mengatakan bahwa seni tari adalah luapan jiwa yang dikomunikasikan melalui irama dan perkembangan yang indah, yang mengandung makna bahwa tari adalah tindakan manusia yang sengaja perlu menyampaikan perasaannya melalui perkembangan musik dan memiliki komponen keindahan. Adapun Iriani, (2012) Seni tari dapat diartikan sebagai keseimbangan komponen gerak, irama dan rasa (wiraga, wirama, wirasa) yang merupakan komponen tari untuk artikulasi, pikiran, dan pesan dengan pendukung cadangan dan ruang atau landasan. Sehingga dapat disimpulkan seni tari adalah ungkapan dan perasaan manusia yang dituangkan dalam sebuah gerakan yang disusun secara sistematis sehingga memiliki makna dan memiliki unsur keindahan serta diiringi musik.

Salah satu seni tari yang ada di Indonesia adalah tari Bungong Jeumpa yang merupakan seni tari daerah Aceh. Bungong Jeumpa dalah bahasa Aceh berarti Bunga Cempaka yang merupakan simbol kebanggaan masyarakat Aceh. Irawan \& Wijayanti, (2019) mengatakan tari bungong jeumpa merupakan tarian tradisional daerah Aceh yang diiringi lagu yang berjudul bungong jeumpa. Tari bungong jeumpa memiliki keunikan seperti gerak tari banyak menggunakan tangan dan kaki, dan hanya diiringi lagu yang berjudul bungong jeumpa (Siti Marta Yuliastuti, Nina Kurniah, 2020). Senada dengan (Restian et al., 2020) yang menyatakan tari bungong jeumpa sebuah tarian daerah Aceh dengan variasi gerak melibatkan tangan, badan, pinggul, dan kaki dan diiringi musik melayu. Jadi dapat disimpulkan tari bungong jeumpa adalah sebuah tarian yang gerakaannya banyak melibatkan tangan, kaki, badan, dan pinggul yang diiringi oleh nyanyian yang sederhana. Maka dalam pengajaran seni tari untuk anak SD tari bungong jeumpa adalah salah satu pilihan yang tepat, karena tarian tersebut memiliki gerakan yang mudah untuk diikuti serta diiringi musik yang sederhana, sehingga dapat merangsang siswa untuk semangat dalam menggerakkan tubuhnya. Alasan pengajaran seni tari di sekolah dasar adalah untuk membantu perubahan selera, mendukung pengembangan dan kemajuan siswa, dan lebih mengembangkan kehidupan. (Iriani, 2012). Pembelajaran seni tidak hanya tertuju pada intelektual 
4702 Pengaruh Media Audio Visual Terhadap Keterampilan Gerak Tari Siswa Sekolah Dasar - Ritu Suwitri, Ana Novitasari, Raimon Effendi

DOI: https://doi.org/10.31004/edukatif.v3i6.1539

saja tetapi juga pada keterampilan dan kreativitas siswa, sehingga dalam implementasi pembelajaran seni membutuhkan media yang dapat menarik perhatian siswa. Kata media berasal dari bahasa latin medius yang secara harfiah berarti 'tenah', 'perantara' atau 'pengantar' (Arsyad, 2020). Adapun menurut (Fitriyani, 2019) mengatakan bahwa media merupakan suatu sarana untuk menyampaikan informasi maupun menyebar gagasan agar tercipta suatu komunikasi.

Berdasarkan pengamatan yang dilakukan peneliti yang pernah melaksanakan Pengenalan Lapangan Persekolahan (PLP) di kelas IV.1 SD Negeri 08 Sungai Rumbai ditemukan permasalahan pada pembelajaran Seni Budaya dan Prakarya (SBdP) khususnya seni tari, seperti kurangnya minat belajar seni tari, kurangnya keseriusan siswa dalam pembelajaran seni tari, kurang antusias dalam mengikuti gerakan tari, dan kemampuan gerak tari siswa yang masih kaku. Sebagaimana permasalahan pada pembelajaran seni tari dalam penelitian (Sustiawati et al., 2018) yaitu, salah satunya ada pada pengembang kurikulum dalam merancang program pembelajaran yang dapat diimplementasikan oleh guru kelas. Kurangnya pengetahuan terutama tentang konsep dan tujuan menari untuk pendidikan, baik dari pihak sekolah, guru, siswa, orang tua murid. Dalam merancang program pembelajaran cenderung pembelajaran seni tari menjadi kurang kreatif. Permasalahan lain dari segi praktik misalnya dalam pelajaran menari di sekolah dasar, siswa diminta untuk menari tarian yang sudah jadi yang terkadang tidak sesuai dengan tingkat perkembangannya, bahkan siswa tidak mengetahui makna tari dan gerak.

Dari masalah yang terjadi rasanya perlu diadakan penelitian bagaimana seharusnya guru memfasilitasi proses pembelajaran pada mata pelajaran SBdP khususnya pada seni tari seperti penggunaan media yang bervariatif dalam proses pembelajaran. Dengan menggunakan media pembelajaran yang bervariatif dapat menumbuhkan semangat belajar siswa. Sependapat dengan (Rosanaya \& Fitrayati, 2021) mengatakan bahwa penggunaan media dalam kegiatan pembelajaran mampu menumbuhkan motivasi dan semangat belajar siswa, sehingga pemahaman siswa terhadap materi yang disampaikan menjadi meningkat.

Media pembelajaran adalah benda yang dapat dipakai untuk mempermudah guru dalam menyampaikan informasi kepada siswa. Darna Yanti, Sartiah Yusran (2019) mengatakan bahwa media pembelajaran merupakan teknik yang digunakan dalam rangka lebih mengefektifkan komunikasi dalam proses pendidikan dan pengajaran di sekolah. Maka dapat disimpulkan media pembelajaran adalah segenap benda yang dapat membantu dalam menyampaikan pesan agar pesan tersebut tersampaikan dan mudah diterima dan dipahami. Adapun beberapa kelebihan media audio visual menurut Maiti \& Bidinger, (2016) misalnya Film dapat menggambarkan siklus secara mendalam, membuat kesan keberadaan, keterbukaan data tiga dimensi, isyarat audio dapat membuat kenyataan dalam gambar sebagai artikulasi murni, dapat menyampaikan suara seorang spesialis dan melihat penampilannya, jika film dan video yang di tampilkan dapat menambah tone pada gambar. Kebenaran item yang diilustrasikan, dan dapat menggambarkan hipotesis dan aktivitas logis.

Untuk mengatasi permasalahan di atas, maka peneliti tertarik untuk melakukan penelitian "Pengaruh Media Audio Visual Terhadap Keterampilan Gerak Tari Siswa Sekolah Dasar”. Dengan tujuan untuk mengetahui apakah ada pengaruh penggunaan media audio visual dalam bentuk video pada keterampilan gerak tari siswa sekolah dasar dan menambah wawasan seluruh pihak dalam mengatasi hambatan dalam pembelajaran seni tari di sekolah.

\section{METODE PENELITIAN}

Jenis penelitian yang digunakan oleh peneliti ini termasuk jenis penelitian eksperimen dengan pendekatan kuantitatif. Metode penelitian eksperimen dapat diartikan sebagai metode penelitian yang digunakan untuk mencari pengaruh perlakukan tertentu terhadap yang lain dalam kondisi yang terkendalikan (Sugiyono, 2019). Desain pada penelitian ini dalam bentuk penelitian one group pretest-posttest design. Berikut pola desain penelitiannya. 
4703 Pengaruh Media Audio Visual Terhadap Keterampilan Gerak Tari Siswa Sekolah Dasar - Ritu Suwitri, Ana Novitasari, Raimon Effendi

DOI: https://doi.org/10.31004/edukatif.v3i6.1539

Keterangan:

\section{$\mathrm{O}_{1} \times \mathrm{O}_{2}$}

\section{Gambar 1. One Group Pretest-Posttest Design}

$\mathrm{O}_{1} \quad=$ Pretest $($ sebelum diberikan perlakuan/treatment $)$

$\mathrm{X} \quad=$ Perlakuan (Treatment)

$\mathrm{O}_{2} \quad=$ Posttest $($ setelah perlakuan/treatment $)$

Pada desain ini terlebih dahulu siswa mempraktikkan gerakan tari bungong jeumpa (pretest), selanjutnya siswa diberi treatment (perlakuan) menggunakan media audio visual kemudian setelah diberi treatment (perlakuan) siswa diminta mempraktikkan kembali gerak tari bungong jeumpa (posttest). Subyek pada penelitian ini adalah seluruh siswa kelas IV.1 SD Negeri 08 Sungai Rumbai, teknik pengambilan sampel menggunakan teknik non-probability sampling dengan bentuk sampling jenuh. Sampling jenuh yaitu strategi penentuan ketika semua individu dari populasi digunakan sebagai tes (Jakni, 2016). Dalam pengumpulan data peneliti menggunakan istrumen. Instrumen adalah perangkat yang digunakan oleh para ilmuwan untuk mengukur nilai faktor yang dipertimbangkan dan mengumpulkan informasi selama peninjauan. Instrumen penelitian bertujuan untuk memudahkan peneliti memperoleh data.

Dalam penelitian ini, peneliti menggunakan lembar tes praktik. Adapun aspek-aspek penilaian tes praktik tari Bungong Jeumpa meliputi gerak berdiri, gerak duduk, hafalan urutan gerak, dan ketepatan gerak dengan musik. Sebelum digunakan dalam penelitian, instrumen diuji coba terlebih dahulu untuk mengetahui validitasnya. Sehingga validitas yang digunakan dalam penelitian ini adalah validitas konstruksi (construct validity), untuk menguji validitas kontruksi dapat menggunakan pendapat dari ahli (judgment experts). Dalam hal ini ahli yang diminta pendapatnya adalah dosen pembimbing peneliti yang dilakukan oleh satu orang dosen sebagai validator instrumen rubrik penilaian keterampilan gerak tari bungong jeumpa.

Teknik pengumpulan data dalam penelitian ini adalah tes praktik yaitu jenis tes yang dapat digunakan oleh peneliti untuk mengumpulkan data, jenis tes yang digunakan yaitu tes kemampuan menarikan tari bungong jeumpa dari hasil penggunaan media Audio Visual berupa pengamatan yang dilakukan oleh siswa selama pembelajaran. Hasil belajar tari Bungong Jeumpa siswa dapat diukur dengan lembar pengamatan tes praktik, dengan menggunakan patokan perhitungan persentase untuk Skala Lima.

\section{Tabel 1}

Persentase Skala Lima

\begin{tabular}{ll}
\hline \multicolumn{1}{c}{$\begin{array}{c}\text { Interval Persentase Tingkat } \\
\text { Pertama }\end{array}$} & Keterangan \\
\hline $85-100$ & Baik sekali \\
\hline $75-84$ & Baik \\
\hline $60-74$ & Cukup \\
\hline $40-59$ & Kurang baik \\
\hline $0-39$ & Gagal \\
\hline
\end{tabular}

Cara penilaian:

Sumber: (Trisnawati, 2013)

Skor penilaian: 100

$$
\text { Nilai Akhir }=\frac{\text { Jumlah skor siswa }}{\text { Jumalah skor maksimal }} \times 100 \%
$$

Teknik analisis data penelitian ini menggunakan analisis data statistik, yaitu uji normalitas dan uji hipotesis. Uji normalitas digunakan untuk mengetahui apakah data yang diperoleh berdistribusi normal atau tidak. Uji normalitas dilakukan dengan bantuan program SPSS 22 menggunakan Uji Shapiro-Wilk dengan 
4704 Pengaruh Media Audio Visual Terhadap Keterampilan Gerak Tari Siswa Sekolah Dasar - Ritu Suwitri, Ana Novitasari, Raimon Effendi

DOI: https://doi.org/10.31004/edukatif.v3i6.1539

ketentuan Signifikansi > 0,05 maka data tersebut berdistribusi normal. Setelah data berdistribusi normal maka dapat dilakukan uji hipotesis.

Berdasarkan pada Uji Shapiro-Wilk hipotesis yang diuji sebagai berikut:

$\mathrm{H}_{\mathrm{o}} \quad$ : Data distribusi tidak normal

$\mathrm{H}_{\mathrm{a}} \quad$ : Data distribusi normal

Perolehan data dari penelitian kemudian dianalisis untuk mengetahui hasil dari penelitian tersebut, analisis data akan membuktikan apakah hipotesis yang diajukan diterima atau di tolak. Pada penelitian ini peneliti menggunakan uji hipotesis test dengan bantuan Program Statistik (SPSS 22).

\section{HASIL DAN PEMBAHASAN PENELITIAN}

Dalam penelitian ini terdapat 32 siswa pada kelas IV.1 SD Negeri 08 Sungai Rumbai yang telah ditetapkan menjadi sampel penelitian. penelitian ini bertujuan untuk mengetahui apakah ada pengaruh media Audio Visual dalam bentuk Video pada keterampilan gerak tari siswa dalam pelajaran Seni Budaya dan Prakarya (SBdP) kelas IV.1 SD Negeri 08 Sungai Rumbai. Sebelum dilakukan perlakuan (treatment), terlebih dahulu peneliti mengambil nilai praktik siswa pada tari Bungong Jeumpa (pretest) sebelum mendapatkan perlakuan (treatment) menggunakan media Audio Visual. Selanjutnya, siswa diberikan treatment (perlakuan) menggunakan media Audio Visual dalam bentuk Video sebanyak dua kali pertemuan. Setelah diberikan perlakuan (treatment), siswa diminta mempraktikkan kembali tari Bungong Jeumpa untuk mengetahui hasil belajar siswa (posttest) setelah mendapatkan perlakuan (treatment) menggunakan media Audio Visual. Selanjutnya data yang diperoleh disajikan menurut Statistic Descriptif data nilai pretest dan posttest pada tabel berikut.

Tabel 2

Data hasil pretest dan posttest siswa

\begin{tabular}{lcccccccc}
\hline & N & Range & Min & Max & Sum & Mean & $\begin{array}{c}\text { Std. } \\
\text { Deviation }\end{array}$ \\
\hline PreTest & 3 & 44 & 44 & 88 & 2163 & 67.59 & 10.373 \\
& 2 & & & & \\
\hline PostTest & 3 & 37 & 57 & 94 & 2431 & 75.97 & 8.567 \\
& 2 & & & & & & \\
\hline $\begin{array}{l}\text { Valid N } \\
\text { (listwise) }\end{array}$ & 2 \\
\hline
\end{tabular}

Berdasarkan analisis data diperoleh nilai rata-rata pretest 67,59 dan nilai posttest 75,97 . Untuk dapat melihat secara jelas perbandingan nilai pretest dan posttest siswa maka peneliti menyajikan dalam bentuk diagram batang berikut ini. 
4705 Pengaruh Media Audio Visual Terhadap Keterampilan Gerak Tari Siswa Sekolah Dasar - Ritu Suwitri, Ana Novitasari, Raimon Effendi

DOI: https://doi.org/10.31004/edukatif.v3i6.1539

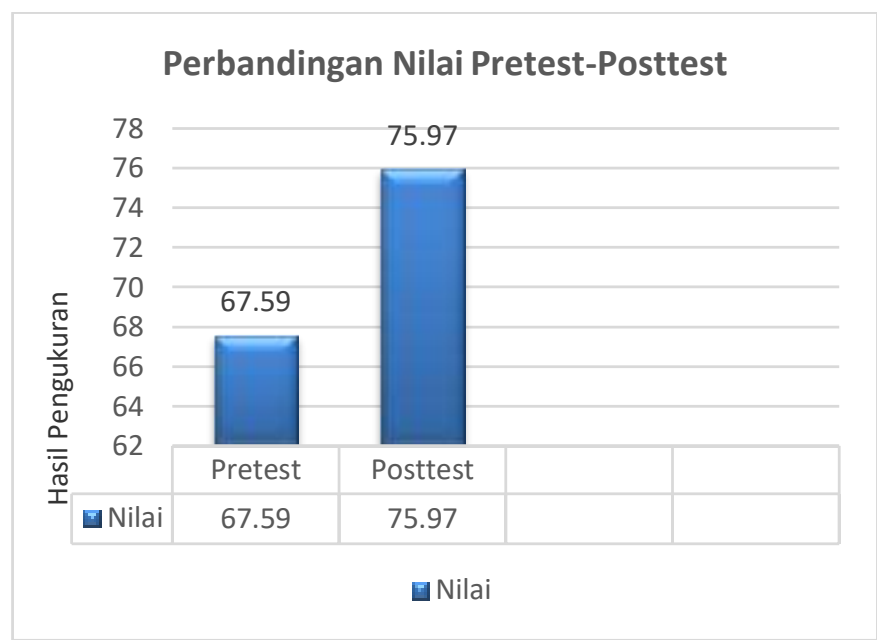

\section{Gambar 2 Perbandingan Nilai Pretest dan Posttest Siswa Kelas IV.}

Gambar 2 menunjukkan perbandingan nilai pretest dan posttest siswa kelas IV.1 SD Negeri 08 Sungai Rumbai. Nilai rata-rata pretest adalah 67,59 sedangkan nilai rata-rata posttest adalah 75,97. Maka selisih nilai rata-rata pretest dan posttest yaitu sebesar 8,38 . Dari selisih tersebut dapat dilihat bahwa perbandingan nilai meningkat dari nilai rata-rata pretest ke nilai rata-rata posttest. Artinya, nilai keterampilan gerak tari siswa meningkat setelah diberi treatment (perlakuan) dengan memanfaatkan media Audio Visual dalam bentuk Video.

Uji normalitas dilakukan dengan bantuan program SPSS 22 menggunakan Uji Shapiro-Wilk, berdasarkan pendapat Suardi, (2019) Mengatakan bahwa Uji Kolmogorov-Smirnov untuk pengujian sampel data di atas 50 sampel sedangkan Shapiro-Wilk digunakan untuk pengujian sampel data kurang dari 50 sampel. Oleh karena itu peneliti menggunakan Uji Shapiro-Wilk karena sampel dalam penelitian ini berjumlah 32 orang. Uji normalitas dilakukan dengan dasar pengambilan putusan jika signifikansi hasil lebih besar dari 0,05 artinya berdistribusi normal. Sedangkan jika signifikansi hasil lebih kecil dari 0,05 artinya tidak berdistribusi normal. Data yang di uji normalitasnya yaitu pretest dan posttest. Berikut adalah tabel uji normalitas data pretest dan posttest siswa kelas IV.1 SD Negeri 08 Sungai Rumbai.

\section{Tabel 3}

Hasil Uji Normalitas Pretest-Posttest

\begin{tabular}{lllll}
\hline \multirow{2}{*}{ Kelas } & & \multicolumn{3}{l}{ Shapiro-Wilk } \\
\cline { 3 - 5 } & & Statistic & df & Sig. \\
\hline Hasil Belajar Siswa & Pretest & .956 & 32 & .208 \\
\hline & Posttest & .946 & 32 & .109
\end{tabular}

Sumber: Data Olahan SPSS 22 (2021)Tabel 3 menunjukkan bahwa signifikansi yang diperoleh data pretest yaitu 0,208>0,05 dan signifikansi yang diperoleh data posttest yaitu 0,109>0,05, artinya data Pretest dan Posttest siswa kelas IV.1 SD Negeri 08 Sungai Rumbai berdistribusi normal. Berikut adalah hasil uji hipotesis penelitian pada tabel di bawah ini. 
4706 Pengaruh Media Audio Visual Terhadap Keterampilan Gerak Tari Siswa Sekolah Dasar - Ritu Suwitri, Ana Novitasari, Raimon Effendi

DOI: https://doi.org/10.31004/edukatif.v3i6.1539

Tabel 4

Hasil Uji Hipotesis Penelitian

\begin{tabular}{|c|c|c|c|c|c|c|c|c|c|}
\hline & & \multicolumn{5}{|c|}{ Paired Differences } & \multirow[b]{3}{*}{$\mathbf{t}$} & \multirow[b]{3}{*}{ df } & \multirow{3}{*}{$\begin{array}{l}\text { Sig. (2- } \\
\text { tailed) }\end{array}$} \\
\hline & & \multirow[b]{2}{*}{ Mean } & \multirow{2}{*}{$\begin{array}{c}\text { Std. } \\
\text { Deviation }\end{array}$} & \multirow{2}{*}{$\begin{array}{l}\text { Std. } \\
\text { Error } \\
\text { Mean } \\
\end{array}$} & \multicolumn{2}{|c|}{$\begin{array}{l}95 \% \text { Confidence } \\
\text { Interval of the } \\
\text { Difference }\end{array}$} & & & \\
\hline & & & & & Lower & Upper & & & \\
\hline $\begin{array}{c}\text { Pair } \\
1\end{array}$ & $\begin{array}{l}\text { PreTest - } \\
\text { PostTest }\end{array}$ & -8.375 & 5.216 & .922 & -10.256 & -6.494 & -9.082 & 31 & .000 \\
\hline
\end{tabular}

Sumber : Olahan Data SPSS 22 (2021)

Berdasarkan tabel 4 diperoleh signifikansi dari uji paired sampels $t$ test yaitu 0,000<0,05 artinya $\mathrm{H}_{0}$ ditolak dan Ha diterima. Maka disimpulkan bahwa terdapat Pengaruh yang signifikan Media Audio Visual dalam bentuk Video Terhadap Keterampilan Gerak Tari Siswa kelas IV.1 SD Negeri 08 Sungai Rumbai. Adapun penelitian penelitian lain yang menunjukkan peningkatan keterampilan menari siswa menggunakan media audio visual. Penelitian ini serupa dengan penelitian ynag dilakukan oleh tersebut (Uba, 2014) menunjukkan hasil penggunaan media audio visual dapat meningkatkan kemampuan siswa memperagakan tari nusantara dan relevan dengan penelitian yang dilakukan oleh (Ananda, 2017) nilai rata-rata kelas eksperimen saat pretest yaitu sebesar 47,00 setelah diberi perlakuan menggunakan media audio visual terdapat peningkatan dengan capaian nilai rata-rata posttest sebesar72,86. Hal ini dibuktikan presentasi keterlaksanaan media audio visual sebesar $81 \%$.

Adapun langkah-langkah pelaksanaan kegiatan penelitian ini yaitu pada awal pertemuan peneliti membahas materi tari Bungong Jeumpa dan mempraktikkan tari Bungong Jeumpa, kemudian peneliti memberi penilaian melalui tes praktik. Pertemuan selanjutnya, peneliti menerapkan metode demonstrasi dan menampilkan media pembelajaran Audio Visual dalam bentuk video dan mempraktikkan tari Bungong Jeumpa dan siswa mengikutinya (selama 2 kali pertemuan). Pertemuan terakhir peneliti memberikan penilaian terhadap siswa dengan melakukan tes praktik tari Bungong Jeumpa yang telah di pelajari. Adapun aspekaspek penilaiannya meliputi, gerak berdiri, gerak duduk, hafalan urutan gerak, dan ketepatan gerak dengan musik.

\section{KESIMPULAN}

Setelah dilakukan penelitian maka terbukti Media Audio Visual dalam bentuk Video dapat berpengaruh terhadap Keterampilan Gerak Tari siswa sekolah dasar. Sehingga penggunaan media audio visual dalam bentuk video dapat dijadikan solusi untuk guru dalam menciptakan pembelajaran yang menyenangkan sehingga siswa aktif dalam mengikuti pembelajaran yang berlangsung. Berdasarkan pengamatan peneliti hasil lain dari penelitian ini adalah meningkatnya minat, keseriusan, dan antusias siswa dalam pembelajaran seni tari.

\section{DAFTAR PUSTAKA}

Ananda, S. R. (2017). Pengaruh Media Audio Visual terhadap Peningkatan Keterampilan Menari Tradisional Peserta Didik Di Sekolah Dasar. Universitas Langlangbuana.

Arsyad, A. (2020). Media Pembelajaran (A. Rahman (ed.); 2020th ed.). Rajawali Pers.

Darna Yanti, Sartiah Yusran, L. I. (2019). Pengaruh Penggunaan Media Audiovisual Terhadap Hasil Belajar Siswa Dalam Pembelajaran Seni Tari Tradisional Lumense Kelas Viii Smp Negeri 16 Poleang Tengah. Pembelajaran Seni \& Budaya, 4(2), 54-60. 
4707 Pengaruh Media Audio Visual Terhadap Keterampilan Gerak Tari Siswa Sekolah Dasar - Ritu Suwitri, Ana Novitasari, Raimon Effendi

DOI: https://doi.org/10.31004/edukatif.v3i6.1539

Fitriyani, N. (2019). Pengembangan Media Pembelajaran Audio-Visual Powtoon Tentang Konsep Diri Dalam Bimbingan Kelompok Untuk Peserta Didik Sekolah Dasar. Jurnal Tunas Bangsa, 6(1), 104-114.

Hanny Pramitha Putri, N. (2021). Pengaruh Media Pembelajaran Power Point Interaktif terhadap Hasil Belajar IPS Siswa Sekolah Dasar. 3(4), 1309-1317.

Irawan, D., \& Wijayanti, O. (2019). Penguatan Pembelajaran Kurikulum 2013 pada Mata Pelajaran SBDP Materi "Kreativitas Pola Lantai Kelompok pada Tari Bungong Jeumpa" (Studi Pelatihan pada Guru MI Muhammadiyah Gumiwang). Seminar Nasional Pagelaran Pendidikan Dasar Nasional 2019, 1(1), 27 35. http://seminar.uad.ac.id/index.php/ppdn/article/view/1444

Iriani, Z. (2012). Peningkatan Mutu Pembelajaran Seni Tari di Sekolah Dasar. Komposisi: Jurnal Pendidikan Bahasa, Sastra, Dan Seni, 9(2). https://doi.org/10.24036/komposisi.v9i2.98

Jakni. (2016). Metodologi Penelitian Pendidikan Eksperimen (Reka Cipta).

Maiti, \& Bidinger. (2016). Peningkatan Kemampuan Menulis Teks Eksplanasi Dengan Menggunakan Media Audiovisual Pada Siswa Sekolah Menengah Pertama. BASASTRA Jurnal Penelitian Bahasa, Sastra Indonesia Dan Pengajarannya, 4(2), 161-174.

Restian, A., Muzakki, A., \& Purnamasari, W. I. (2020). Model Pembelajaran Talking Stick Melalui Permainan Truth or Dare Pada Tari Bungong Jeumpa Kelas IV Sekolah Dasar. Jurnal Satwika, 4(1), 1. https://doi.org/10.22219/satwika.vol4.no1.1-9

Rosala, D. (2016). Pembelajaran Seni Budaya Berbasis Kearifan Lokal Dalam Upaya Membangun Pendidikan Karakter Siswa Di Sekolah Dasar. Ritme, 2(1), 16-25.

Rosanaya, L. S., \& Fitrayati, D. (2021). Pengembangan Media Pembelajaran Berbasis Video Animasi pada Materi Jurnal Penyesuaian Perusahaan Jasa. Edukatif: Jurnal Ilmu Pendidikan, 3(5), 2258-2267.

Setiawan, A. (2019). Mengembangkan Nilai Karakter dan Kemampuan 4C Anak Melalui Pendidikan Seni Tari di Masa Revolusi Industri 4.0. Didaktis: Jurnal Pendidikan Dan Ilmu Pengetahuan, 19(2), 193211. https://doi.org/10.30651/didaktis.v19i2.2958

Siti Marta Yuliastuti, Nina Kurniah, M. A. (2020). Penerapan Metode Latihan Dengan Menggunakan Media Audio Visual Dalam Tari Kreasi Untuk Meningkatkan Motorik Kasar Pada Kelompok B. Jurnal Ilmiah Potensia, 5(1), 25-30. file:///C:/Users/Windows 10 Pro/Downloads/Jurnal sbdp/d.bungong jeumpa.pdf

Suardi. (2019). JBEE : Journal Business Economics and Entrepreneurship. Journal Business Economics and Entrepreneurship, 1(2), 1-6.

Sugiyono. (2019). Metode Penelitian Kuantitatif, Kualitatif, Dan R\&D (2017th ed.).

Sujana, I. W. C. (2019). Fungsi Dan Tujuan Pendidikan Indonesia. Adi Widya: Jurnal Pendidikan Dasar, 4(1), 29. https://doi.org/10.25078/aw.v4i1.927

Sustiawati, N. L., Suryatini, N. K., \& Mayun Artati, A. A. A. (2018). Pengembangan Desain Pembelajaran Seni Tari Di Sekolah Dasar Berbasis Localgenius Knowledge Berpendekatan Integrated Learning. Mudra Jurnal Seni Budaya, 33(1), 128. https://doi.org/10.31091/mudra.v33i1.322

Trisnawati, N. H. (2013). Penggunaan Media Audio Visual Pada Pembelajaran Tari Sigeh Penguten Kelas IV B Di SD Negeri 1 Bandar Lampung. In Paper Knowledge. Toward a Media History of Documents.

Uba, Y. (2014). Meningkatkan Kemampuan Siswa Dalam Memperagakan Tari Nusantara Melalui Media Audio Visual Di Kelas V SDN 4 Tabongo Kabupaten Gorontalo. U. 